\title{
Transcriptomic analysis suggests candidate genes for hygienic behavior in African-derived Apis mellifera honeybees
}

\author{
Érica Weinstein TeIXeIrA ${ }^{1}$, Raquel Morais de PAIVA DaIBerT ${ }^{2}$ (i), \\ Luiz Afonso Glatzl JúNIOR ${ }^{2}$, Marcos Vinicius Gualberto Barbosa da Silva ${ }^{2}$, \\ Maria Luisa Teles Marques Florencio Alves ${ }^{1}$, Jay Daniel Evans ${ }^{3}$, Amy Lynn Tотн ${ }^{4}$ \\ ${ }^{1}$ Laboratório Especializado de Sanidade Apícola (LASA)/Instituto Biológico/APTA/SAA-SP, Pindamonhangaba, SP \\ 12411010, Brazil \\ ${ }^{2}$ Empresa Brasileira de Pesquisa Agropecuária, Embrapa Gado de Leite, Rua Eugênio do Nascimento, 610 - Dom Bosco, \\ Juiz de Fora, MG 36038330, Brazil \\ ${ }^{3}$ USDA-ARS, Bee Research Laboratory, BARC-East Building 306, Beltsville, MD 10 20705, USA \\ ${ }^{4}$ Departments of Ecology, Evolution, Organismal Biology and Entomology, Iowa State University, 251 Bessey Hall, \\ Ames, IA 50011, USA
}

Received 1 June 2020 - Revised 11 November 2020 - Accepted 15 December 2020

\begin{abstract}
Hygienic behavior is a social defense mechanism against parasites and pathogens in honeybees. We studied the genetic basis of hygienic behavior in African-derived Apis mellifera by performing RNA sequencing on brains of individual honeybee workers observed performing hygienic behavior, in order to identify expression changes linked with this behavior. We also used the transcriptome data to search for single nucleotide polymorphism (SNP) variation in genes previously associated with the trait in other $A$. mellifera populations. The analysis revealed 49 differentially expressed genes (DEG), most of them upregulated during hygienic acts. One DEG, Apidaecin, also showed SNP variation across samples, providing a promising candidate gene for both expression-based and heritable variation in hygienic behavior. We also identified 27 additional SNPs in the coding regions of five candidate genes previously linked with honeybee hygienic behavior. These results provide a useful starting place to analyze the genetic basis of hygienic behavior in African-derived honeybees.
\end{abstract}

\section{AHB / Marker-assisted / Disease-resistance / Selection}

\section{INTRODUCTION}

Honeybees (Apis mellifera L.) live in colonies with high densities of relatives and therefore are subject to high pressure from infectious diseases (Cremer et al. 2007; Evans and Spivak 2010; Brosi et al. 2017). Similar to other social insects,

Corresponding author: R. Paiva Daibert,

rqmpaiva@gmail.com

Manuscript editor: Klaus Hartfelder

The dataset used is now now publicly available at https://www.ncbi.nlm.nih.gov/bioproject/PRJNA631022 honeybees have collective social behavioral defenses to combat these threats. This so-called social immunity can be prophylactic or activated on demand to prevent parasite entrance, establishment, and spread (Cremer et al. 2007).

Hygienic behavior is one of honeybees' defense mechanisms against pests and diseases including the mite Varroa destructor (Spivak and Downey 1998; Harbo and Harris 2009; Danka et al. 2011), chalkbrood disease caused by Ascosphaera apis (Gilliam et al. 1983; Spivak and Downey 1998; Spivak and Reuter 2001), and American foulbrood caused by 
Paenibacillus larvae (Spivak and Reuter 1998; Rauch et al. 2009). Hygienic behavior consists largely of middle-age specialized workers (1517 days old) that detect larvae and pupae infected by brood diseases and then uncap the brood cell and remove these larvae, thereby preventing the proliferation of infection to other individuals, which could result in colony death (Rothenbuhler 1964; Arathi et al. 2000; Wilson-Rich et al. 2009). Many breeding programs have focused on pest- and diseaseresistance mechanisms when developing biological targets for artificial selection (Masterman et al. 2001; Spivak et al. 2003; Harbo and Harris 2009; Le Conte et al. 2011; Parker et al. 2012; Tsuruda et al. 2012; Boutin et al. 2015; Gempe et al. 2016; Jiang et al. 2016; Guarna et al. 2017; Wagoner et al. 2018). Hygienic behavior in particular has been of high interest to honeybee breeding programs all over the world (Gerdts et al. 2018); this behavior can not only improve colony survival in the face of disease agents, but has also been connected to propolis production and increased honey and pollen stores (Nicodemo et al. 2013).

In this context, there has been great interest in understanding the genetic basis of hygienic behavior as both an applied breeding trait and an adaptation to social life. In 1964, Rothenbuhler hypothesized that this behavior depends on two recessive genes (designated $u$ and $r$ ), occurring in homozygosis. The $u$ gene determines the tendency to uncap brood and the $r$ gene the removal of dead larvae. More recent studies on the genetics and evolution of loci associated with hygienic behavior in honeybees suggest a more complex genetic architecture of this trait (Moritz 1988) and led to efforts to find genomic regions as QTLs (quantitative trait loci) for this trait (Oxley et al. 2010; Spötter et al. 2012; Harpur et al. 2019).

Genomic approaches including transcriptomics (such as RNA-sequencing, or RNA-seq) have fueled modern efforts to identify the mechanistic basis of hygienic behavior in bees ( $\mathrm{Ji}$ et al. 2014a, b; Boutin et al. 2015; Mondet et al. 2015). For example, whole genome resequencing identified 73 candidate genes associated with hygienic behavior, several of which are related to neuronal development and early axon guidance and sensory perception (Harpur et al. 2019). Other studies have investigated global gene expression patterns, and how they correlate with the hygienic phenotype in honeybees (Navajas et al. 2008; Le Conte et al. 2011; Gempe et al. 2012, 2016; Ji et al. 2014a, b; Boutin et al. 2015).

However, all studies conducted so far approach populations of European honeybees (EHB) or Apis cerana species and there are no studies investigating gene expression with respect to hygienic behavior in African-derived honeybees (AHB, a variant of A. mellifera). These bees, widely distributed throughout tropical and subtropical regions, including the American continent (Harrison et al. 2006), appear to be especially resistant to disease. It has been suggested that high levels of hygienic behavior contribute to this trait (Carneiro et al. 2007; Rosenkranz et al. 2010), including other genetically determined characteristics like higher heritability of grooming behavior (Moretto et al. 1993), contributing to AHB's highly effective anti-parasite defensive capacity (Moretto and Mello-Jr 1988) and suppressed Varroa mite reproduction (Camazine 1986; Moretto and Mello-Jr 1988), associated with the short development time of this biotype in relation to European-subspecies (Michelette and Soares 1993). Other traits that may contribute to parasite and disease-resistance in AHB are high-efficiency filtering of parasites prior to entering the gut via the proventriculus (Peng and Marston 2008), as well as high production of propolis, resins collected by honeybees and spread on the inside of the hive, which that may provide additional antipathogen defense (Simone-Finstrom and Spivak 2012). AHB are hybrids, resulting from decades of introgression of European subspecies of Apis mellifera and the African subspecies A. m. scutellata, introduced into Brazil in 1956. Many questions remain about the remarkably successful biological invasion throughout much of the New World by African-derived bees (Schneider et al. 2004).

In our study, we used transcriptional profiling with RNA-seq to probe the genetic basis of hygienic behavior in AHB. We searched for genes actively regulated in association with the performance of hygienic behavior (uncapping and 
removing sick or dead brood) by examining gene expression in brains of individual bees actively engaged in hygienic behavior and comparing these bees to individual bees that had never been observed performing the behavior. We also searched for SNP variants within the AHB population for genes identified from this and previous studies to be associated with hygienic behavior, as a first step towards developing marker-assisted selection for this trait.

\section{MATERIAL AND METHODS}

\subsection{Biological samples}

We used an apiary with 60 AHB colonies formed by mated queens received from beekeepers of Minas Gerais and São Paulo states (Brazilian Southeast Region) and from the São Paulo State Agribusiness Technology Agency (APTA) located in Pindamonhangaba, São Paulo, Brazil ( $22^{\circ} 57^{\prime} \mathrm{S}, 45^{\circ} 27^{\prime} \mathrm{W}, 560 \mathrm{~m}$ of altitude).

The colonies were installed in Langstroth hives. Sugar and protein feed were provided weekly, and hive checks were carried out regularly to monitor hive growth, with the goal of standardizing population status and productive capacity of all hives. We used the pin-killing test (pinkeyed pupae 10 to 14 days old) according to Gramacho et al. (1999) to phenotype and classify colonies as hygienic (those that removed an average of $80 \%$ or more of affected brood) or nonhygienic (less than $80 \%$ of the dead brood removal), $24 \mathrm{~h}$ after pin-killing the brood. The process was repeated three times, consecutively.

Fifteen colonies, with hygienic scores ranging from 83.1 to $98.7 \%$, were selected to produce new queens. When necessary, tie-break criteria were adopted including low pathogenic infection load with Nosema ceranae, low infestation with Varroa destructor, largest general population, and unbroken patterns of brood sealed area. Four unmated daughter queens from each of the 15 queens selected above were reared, using standard beekeeping "grafting" techniques (Büchler et al. 2013), and naturally mated to free-flying drones, producing 60 new colonies (F1 generation), which were established in the same location. This process was repeated one more time, and combs with brood (F2 generation) from hygienic hives were collected. Workers from those combs emerged in an incubator and were marked with colored numbered discs.

Four observation hives with entrances open to the outdoors (through the wall of the laboratory building housing these hives) were subjected to the pin-killing test (pink-eyed pupae, 10 to 14 days), according Gramacho et al. (1999). These observation hives received the emerged marked bees in a chamber located above two colony frames (containing honey and brood combs). The opening between the chamber and the frames was blocked with candy paste (confectioner's sugar and honey) to allow gradual passage of the marked workers to the observation hives as the paste was consumed by the bees. The hives were observed for 7 days, $12 \mathrm{~h}$ per day. The focal bees (marked) were observed continuously during this period and collected immediately after observed performing the behavior.

We collected 11 bees for brain RNA extraction and RNA-seq analysis, as described below. Individuals were observed performing uncapping only (UN) or uncapping and brood removal (RE) behaviors, both referred as "hygienic activity" (HA, $n=5$ ). Individuals not observed performing any of these behaviors were referred to as "no hygienic activity" (NA, $n=6$ ). Both HA and NA bees originated from the same three queen bees, derived from three colonies, which overlapped between the HA and NA groups (Supplementary Table 1).

Furthermore, we searched for viral infections that may interfere on the gene expression analysis between hygienic and non-hygienic bees. We used the subsequently generated RNA-seq data to search for viral presence in colonies. For that we aligned the paired-end, quality-controlled reads against an index of viruses found in A. mellifera (an updated virus sequence set from HolobeeBar at https://data.nal. usda.gov/dataset/holobee-database-v20161) using Hisat2 with default parameters $(-1-2-\mathrm{S}-\mathrm{dta})$ to show the presence/absence of different viruses and to verify the homogeneity of viral load in colonies.

\subsection{RNA extraction}

We collected worker bees (aged 14 days), UN and RE individuals (HA), as well as individuals who showed neither behavior (NA; Table 1). The 
Table 1. Samples collected in observation hives and classified according to individual behavior. Individual bees were 14 days old and classified by their behavior as performing hygienic activity (HA) or not, no hygienic activity (NA). Bees in the HA group were further subdivided into subcategories depending on whether they were observed uncapping only or uncapping and removing brood (however, this information was not used in any subsequent analysis and both were grouped together as HA). Bees in the control group (NA) did not uncap or remove brood during the entire period that they were observed ( 7 days, $12 \mathrm{~h}$ per day)

\begin{tabular}{|c|c|c|}
\hline Group (age) & Sample ID & Observed behavior \\
\hline \multirow{6}{*}{$\begin{array}{l}\text { Control: no hygienic activity } \\
\text { (14 days) }\end{array}$} & NA1 & No hygienic activity \\
\hline & NA2 & No hygienic activity \\
\hline & NA3 & No hygienic activity \\
\hline & NA4 & No hygienic activity \\
\hline & NA5 & No hygienic activity \\
\hline & NA6 & No hygienic activity \\
\hline \multirow{5}{*}{$\begin{array}{l}\text { Behavioral: hygienic activity } \\
\text { (14 days) }\end{array}$} & HA1 & Uncapping brood \\
\hline & HA2 & Uncapping brood \\
\hline & HA3 & Uncapping and removing brood \\
\hline & HA4 & Uncapping and removing brood \\
\hline & HA5 & Uncapping and removing brood \\
\hline
\end{tabular}

collection at 14 days was made for necessary standardization in the expression analysis, although for some of the bees we do noted only uncapping or removing and uncapping before the 14 days. NA bees were not seen responding at all for the entire week.

We analyzed UN and RE as a single group compared with bees not observed performing the behavior (NA). The collected individuals were submersed immediately in liquid nitrogen and stored in RNA later ${ }^{\circledR}$ Tissue Collection (Ambion) at $-80^{\circ} \mathrm{C}$ until brains were dissected from each individual bee. RNA from bee brains was extracted with the RNeasy Mini Kit (Qiagen), according to the manufacturer's instructions, and was then stored at $-80^{\circ} \mathrm{C}$.

\subsection{Library construction and RNA sequencing}

We sequenced mRNA from 11 bee brains, between HA $(n=5)$ and NA $(n=6)$ samples. Libraries were prepared with TruSeq RNA sample preparation kit (Illumina), according to the manufacturer's recommendations, at the Iowa State University DNA Facility. In brief, total RNA was purified to obtain mRNA, using poly-T oligo-attached magnetic beads, and then fragmented. RNA fragments primed with random hexamers were reverse transcribed into first strand cDNA using reverse transcriptase (SuperScript II) and random primers. Then the cDNA was converted into doublestranded DNA and subjected to library preparation, according to the manufacturer's protocol, with ligation of a single adenine (A) nucleotide in the $3^{\prime}$ ends of the blunt generated fragments to prevent them from ligating to one another. Adapters were ligated to the cDNA samples, then hybridized onto a flow cell and amplified by PCR. The quality of the libraries was checked using an Agilent Technologies 2100 Bioanalyzer with Agilent DNA1000 kit, following the manufacturer's protocol. Before sequencing, all samples were normalized and pooled together using the adapter indices provided in the kit. Samples were sequenced in singleend read mode (1x), with 100 bp reads, on a HiSeq 3000 machine (Illumina) at the DNA Facility at Iowa State University. The raw data presented in this article were deposited to NCBI Short Read Archive (http://www.ncbi.nlm.nih.gov/sra/) and are accessible through SRA accession number: SUB7396440 (temporary submission ID) and BioProject ID: PRJNA631022. 


\subsection{Quality control and RNA-seq analysis}

Quality control of each raw read data file was initially confirmed using FastQC software v0.11.5 (http://www.bioinformatics.babraham.ac. $\mathrm{uk} /$ projects/fastqc).

We performed the RNA-seq analysis with CLC Genomics workbench 12 (Qiagen Bioinformatics). Briefly, we mapped the reads against the bee reference genome (Amel_HAv3.1, from NCBI database - ncbi.nlm.nih.gov; Wallberg et al. 2019 ), using the default parameters: (a) maximum number of mismatches $=2$, (b) minimum length and similarity fraction $=0.8$, and (c) maximum number of hits per read $=10$. Expression values were measured as total counts. One HA sample (HA3) resulted in a very small number of total reads and was dropped from further analysis.

\subsection{Identification of differentially expressed genes (DEGs)}

Gene expression was calculated with CLC Genomics Workbench 12 (Qiagen Bioinformatics) based on the bee genome (Wallberg et al. 2019) as well as the annotation file GCF_003254395.2_Amel_HAv3.1_genomic, downloaded from the NCBI database. For differential expression analysis, we used the "RNA-Seq Analysis" tool in CLC Genomics Workbench. We used the "Whole transcriptome RNA-Seq technology" and "Genome annotated with genes and transcripts" options, normalized by the TMM (Trimmed Mean of M-values) method. In this study, genes were considered as statistically significantly differentially expressed when FDR (false discovery rate) adjusted $p$ values $\leq 0.05$ and with an absolute fold change of \pm 2 . We performed differential expression analysis by contrasting all NA versus all HA samples. Source queen was not included as a random factor because there were too few replicates per queen (Supplementary Table 1) to estimate the variance associated with queen with reasonable precision.

\subsection{Functional annotation of DEGs}

The Database for Annotation, Visualization and Integrated Discovery version 6.8 (DAVID, http://david.abcc.ncifcrf.gov/; Huang et al. 2009 $\mathrm{a}, \mathrm{b})$ was used for Gene Ontology analysis (GO) of statistically significant DEGs (FC $\geq 2$; FDR $p$ value $\leq 0.05$ ), considering only processes with significant enrichment against the background set of all genes in the transcriptome dataset at $p$ value $<0.05$. Among GO terms, biological process (BP), cellular component (CC), and molecular function (MF) were evaluated.

\subsection{SNP analysis}

We performed SNP calling with CLC Genomics Workbench software (Qiagen Bioinformatics) based on the mapped RNA-seq data from the same 10 samples used in the previous DEGs analysis, as described above. SNP detection was performed using the "Variant Detection" method in the software, with parameters set as minimum quality of each read central base at 40 , minimum coverage at $10 x$, minimum count at 2 , and minimum variant frequency at $35 \%$. SNP calling was performed with all samples analyzed (HA and NA) for polymorphism identification. Other filter parameters were based on CLC Genomics Workbench default settings.

Because the Amel_HAv3.1 reference genome (Wallberg et al. 2019) assembly was based on EHB, it could introduce some biases to the AHB analysis. To minimize this, in SNP calling, we only considered polymorphisms with differences in zygosity between the two studied behavioral groups (HA and NA) as potentially informative SNPs.

We searched specifically for SNPs within the 49 DEGs for the contrast between NA and HA groups, focusing on those with high magnitude of expression difference (above 40-fold overexpressed). Moreover, based on previously published literature (Spivak and Reuter 2001; Navajas et al. 2008; Le Conte et al. 2011; Boutin et al. 2015; Harpur et al. 2019; Conlon et al. 2019), we selected 32 additional genes related to hygienic behavior in EHB and searched for SNPs in these based on our African-derived honeybee RNA-seq data. We then used the Linux (Linux Foundation) command $a w k$ to search for the identified SNPs in each sample, filtering by coverage $>7$ and average quality $>40$. SNPs were considered relevant 
only if they occurred in at least four samples and were considered "potentially informative" if homozygous or heterozygous in all samples of one group (HA or NA) and the opposite zygosity in the other group.

\section{RESULTS}

\subsection{Presence of viruses}

We verified that the viral load of colonies was homogeneous by aligning the paired-end, qualitycontrolled reads against an index of viruses found in A. mellifera (Ray et al. 2020). For all bee samples (non-hygienic and hygienic), we found the presence of viral sequences (Supplementary Table 2). However, because there were no differences between HA and NA groups, this should not introduce bias into our group comparisons. Also, all colonies showed high activity and the absence of overt symptoms related to viral infection; thus, although bees carried viruses, it is unlikely that negative health effects of viral infection interfered with our behavioral phenotyping or sequencing.

\section{DISCUSSION}

To our knowledge, this is the first study to uncover links between hygienic behavior and differential gene expression in AHB. This behavior is of particular interest in AHB due to their relatively high levels of disease-resistance compared with European-derived honeybees (Piccirillo and De Jong 2003; Hamiduzzaman et al. 2015), and the fact that these bees are widely distributed and utilized for beekeeping throughout much of South, Central, and North America (Harrison et al. 2006). Here, we used RNA-seq transcriptional profiling as a discovery tool to uncover gene expression and genetic differences between hygienic and non-hygienic AHB, identifying numerous differentially expressed genes and searching for SNPs genes related with the behavior from this and prior studies in European-derived honeybees (Spivak and Reuter 2001; Navajas et al. 2008; Le Conte et al. 2011; Boutin et al. 2015; Harpur et al. 2019; Conlon et al. 2019).

Our differential expression results reveal both previously unknown and shared genes associated with hygienic behavior in AHB (Supplementary Table 3). For example, our DEGs results overlap with some genes previously identified by Boutin et al. (2015) involved in hygienic behavior in hybrid Italian/Buckfast honeybees. For example, that study also found over-expression of TpnI, $T p n T$, and LOC408608 in non-hygienic honeybees, similar to our findings (Table 3 ), suggesting shared mechanisms for hygienic behavior in different genetic backgrounds of honeybees.

The DEGs we identified associated with hygienic activity (HA) were enriched for the biological processes of defense response to bacteria and

Table 2.. Summary statistics of RNA-seq data and SNP information. Number of total (raw) and mapped reads and their mapping percentage generated by RNA sequencing of AHB brains and number of totals found variants (SNPs)

\begin{tabular}{llllc}
\hline Sample ID & Raw reads & Mapped reads & Mapped reads $(\%)$ & Total variant \\
\hline NA1 & $19,966,313$ & $16,719,361$ & 83.84 & 14,495 \\
NA2 & $18,885,127$ & $14,977,009$ & 79.37 & 50,860 \\
NA3 & $15,446,157$ & $14,076,286$ & 91.24 & 30,443 \\
NA4 & $34,388,243$ & $28,561,311$ & 83.24 & 67,435 \\
NA5 & $27,422,580$ & $24,556,659$ & 89.79 & 28,864 \\
NA6 & $46,114,520$ & $43,789,262$ & 94.99 & 18,692 \\
HA1 & $16,477,446$ & $12,307,143$ & 75.63 & 36,367 \\
HA2 & $33,968,207$ & $20,130,112$ & 59.41 & 22,153 \\
HA4 & $17,450,484$ & $14,616,955$ & 83.84 & 50,036 \\
HA5 & $26,737,359$ & $23,174,114$ & 86.96 & 55,450 \\
\hline
\end{tabular}


Table 3. Genes with the highest magnitude of differential expression (above 40-fold). Region column denotes the initial and final position of each gene on its respective chromosome (Column 2). The Fold change column shows the fold difference in expression between African-derived honeybee brains observed performing hygienic activity (HA, $n=4$ ) versus no hygienic activity (NA, $n=6$ )

\begin{tabular}{llllll}
\hline \multicolumn{1}{c}{ Gene } & Chromosome & \multicolumn{1}{c}{ Region } & Fold change & $\mathrm{p}$ Value & FDR $p$ value \\
\hline TpnT & 6 & $2,064,267 . .2079739$ & 41,72 & $2,7 \mathrm{E}-08$ & $6,1 \mathrm{E}-05$ \\
Melt & 4 & $12,397,548 . .12399076$ & 42,54 & $2,9 \mathrm{E}-06$ & 0,002 \\
TpnI & 2 & $14,369,041 . .14397205$ & 49,16 & $4,4 \mathrm{E}-10$ & $5,0 \mathrm{E}-06$ \\
LOC406114 & 13 & $9,129,778 . .9132956$ & 72,92 & $5,8 \mathrm{E}-08$ & $9,3 \mathrm{E}-05$ \\
LOC408608 & 1 & $7,780,836 . .7781974$ & 111,05 & $1,0 \mathrm{E}-05$ & 0,005 \\
LOC408532 & 15 & $5,753,707 . .5756482$ & 728,87 & $2,7 \mathrm{E}-05$ & 0,011 \\
\hline
\end{tabular}

innate immune response (Table 4). The honeybee innate immune system is responsible for pathogen recognition and signaling pathways that culminate in the expression of proteins that limit the impacts of infection (Evans et al. 2006). Because hygienic bees often remove diseased brood, they may in the process expose themselves to pathogens, which could in turn lead to the induction of immune response genes.

One of the DEGs, Apid1, codes for Apidaecin, which is an innate immune component that defends against microbial invasion ( $\mathrm{Li}$ et al. 2006) and is a prominent component of honeybee humoral defense (Xu et al. 2009). This immune system defense is potentially important for hygienic behavior because it depends on a set of generally acting recognition proteins against pathogens, culminating in the expression of proteins that eliminate or reduce the pathogenic threat through downstream signaling pathways. We observed downregulation of Apid1 in hygienic individuals (HA) compared with individuals not observed to perform hygienic activity (NA; Table 3). Although it is unclear why hygienic bees would downregulate an antimicrobial peptide, one possibility is that the immune systems of these bees were not actively fighting a bacterial infection (as antimicrobial peptide expression is often induced by an infection (Wu et al. 2018)), allowing them to disinvest in the expression of these peptides, perhaps investing in other immune components such as antifungal or antiviral activity. The fact that this gene was differentially expressed and also contained SNP variation between hygienic and non-hygienic bees suggests this gene could be a good target for marker-assisted selection.

Boutin et al. (2015) also found an association between the Syn 1 gene and hygienic colonies. We did not find differential expression of this gene, but we investigated the presence of SNPs in this gene and discovered three relevant polymorphisms, located in exonic region, in the sampled AHB individuals (Table 5).

Another gene of interest from our study is the abscam gene, which codes for a cell adhesion protein with a putative function in axon guidance. This protein has previously been described to be highly expressed in bee brains, decreasing with age (0-14 days after eclosion; Funada et al. 2007). We found this gene in our RNA-seq dataset, but it was not statistically differentially expressed (FDR $p$ value $=1$ ). Harpur et al. (2019) identified this gene as a candidate for hygienic behavior in European-derived honeybees, leading us to investigate whether it may contain SNPs in AHB. We identified a large number (14) of relevant SNPs (Table 5), including three potentially informative SNPs: 1,638,247; 1,638,290; and 1,638,295.

Another interesting gene, Obp4, for which we found two SNPs, both in located in exons, corresponds to a previously discovered QTL Uncap1, associated with uncapping behavior in Europeanderived honeybees (Oxley et al. 2010; Boutin et al. 2015). According to Oxley et al. (2010), this region seems to explain some phenotypic variation in hygienic activity, and, therefore, we suggest it as a potential candidate marker, as this 
Table 4. GO enrichment for DEGs between African-derived Honeybee brains presenting no hygienic activity (NA, $n=6$ ) versus hygienic activity (HA, $n=4)$. BP indicates biological process, CC indicates cellular component, and MF indicates molecular function. Category column gives the category of the enriched GO term. Term column denotes the enriched term (in bold) and the enriched genes name below each term. Columns count and \% denotes the number of genes for each presented term and their percentage, respectively.

\begin{tabular}{|c|c|c|c|c|c|}
\hline Category & Term & Count & $\%$ & $p$ value & $\begin{array}{l}\text { Benjamini } \\
\text { adjusted } \\
p \text { value }\end{array}$ \\
\hline GOTERM_BP & $\begin{array}{l}\text { Defense response to bacterium } \\
\text { GENE NAME } \\
\text { Apidaecin } 1 \text { (Apid1) } \\
\text { Hymenoptaecin (LOC406142) }\end{array}$ & 2 & 3,8 & $\begin{array}{c}3,70 \mathrm{E}- \\
02\end{array}$ & $3,80 \mathrm{E}-01$ \\
\hline GOTERM_BP & $\begin{array}{l}\text { Innate immune response } \\
\text { GENE NAME } \\
\text { Apidaecin } 1 \text { (Apid1) } \\
\text { Hymenoptaecin (LOC406142) }\end{array}$ & 2 & 3,8 & $\begin{array}{c}4,40 \mathrm{E}- \\
02\end{array}$ & $2,60 \mathrm{E}-01$ \\
\hline GOTERM_CC & $\begin{array}{l}\text { Extracellular region } \\
\text { GENE NAME } \\
\text { Apidaecin } 1 \text { (Apid1) } \\
\text { Melittin (Melt) } \\
\text { Orcokinin peptide (LOC726294) } \\
\text { Waprin-Phi1-like (LOC408864) }\end{array}$ & 4 & 7,5 & $\begin{array}{c}6,90 \mathrm{E}- \\
03\end{array}$ & $6,10 \mathrm{E}-02$ \\
\hline GOTERM_CC & $\begin{array}{l}\text { Troponin complex } \\
\text { GENE NAME } \\
\text { Troponin I (TpnI) } \\
\text { Troponin T, skeletal muscle (TpnT) }\end{array}$ & 2 & 3,8 & $\begin{array}{c}7,20 \mathrm{E}- \\
03\end{array}$ & $3,20 \mathrm{E}-02$ \\
\hline GOTERM_MF & $\begin{array}{l}\text { Calcium ion binding } \\
\text { GENE NAME } \\
\text { Myosin light chain alkali (LOC410058) } \\
\text { Myosin regulatory light chain } 2 \text { (LOC409881) } \\
\text { Troponin C type I (TpnCI) } \\
\text { Troponin C type IIIa (TpnCIIIa) }\end{array}$ & 4 & 7,5 & $\begin{array}{c}1,50 \mathrm{E}- \\
02\end{array}$ & $3,00 \mathrm{E}-01$ \\
\hline GOTERM_MF & $\begin{array}{l}\text { Copper ion binding } \\
\text { GENE NAME } \\
\text { Lysyl oxidase homolog } 4 \text { (LOC408544) } \\
\text { Phospholipase B1, membrane-associated-like } \\
\quad \text { (LOC552829) }\end{array}$ & 2 & 3,8 & $\begin{array}{c}4,90 \mathrm{E}- \\
02\end{array}$ & 4,50E-01 \\
\hline
\end{tabular}

locus may be predictive of whether workers perform uncapping behavior (Oxley et al. 2010).

The gene coding for cacophony protein (cac) has previously been found to be highly expressed in hygienic European-derived honeybees (Boutin et al. 2015). The $c a c$ gene, which is involved in neurotransmitter release via a voltage-gated presynaptic $\mathrm{Ca}^{++}$channel in Drosophila (Kuromi et al. 2004) showed the second highest level of relevant SNP markers, all located in intronic regions. Although in less abundant levels, the RNAseq technique also capture intronic sequences from pre-mRNA (Sultan et al. 2008; Gaidatzis et al. 2015). Three of five samples that had the marker at gene position 2,521,065 were homozygous, all were NA individuals, and the other two 


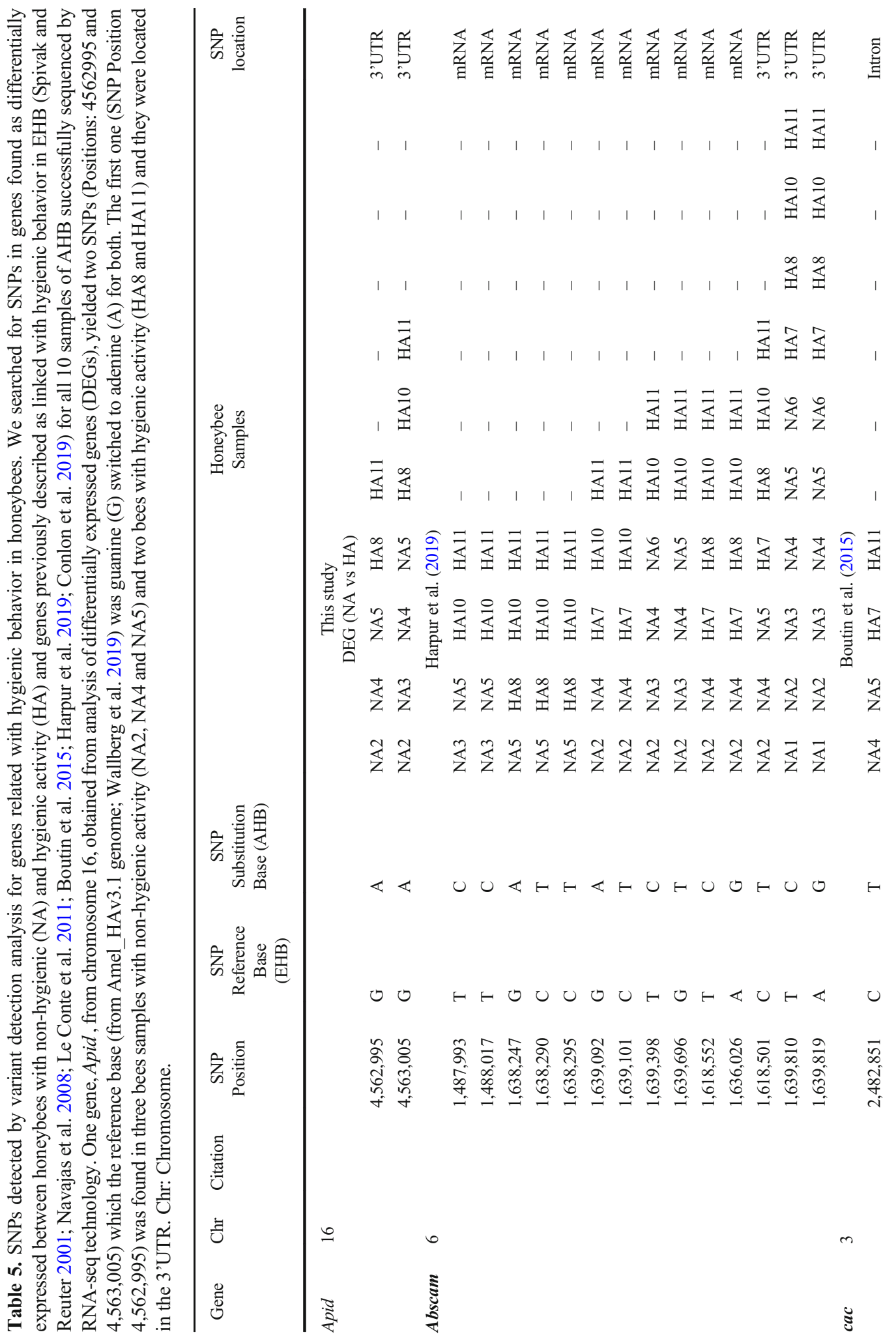




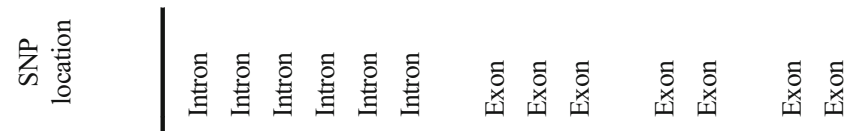
$\Xi \Xi$

志

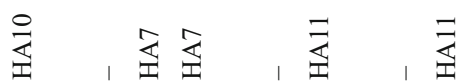

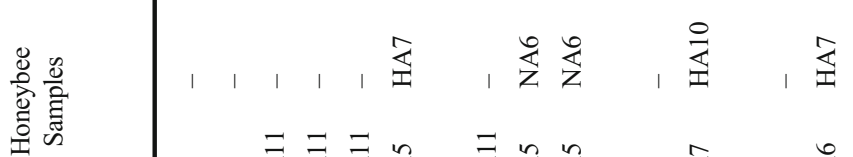

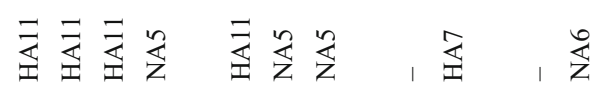

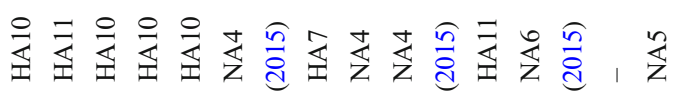

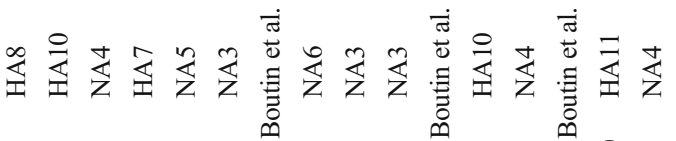

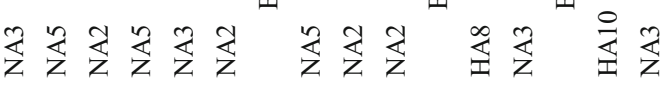

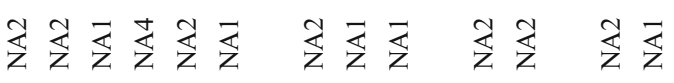

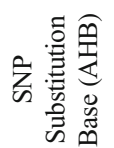

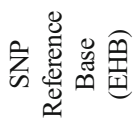

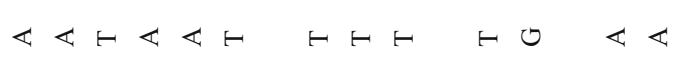

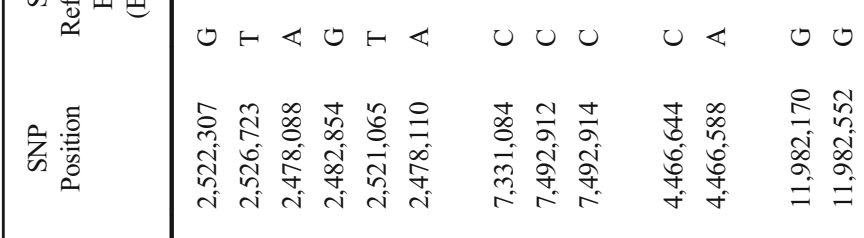

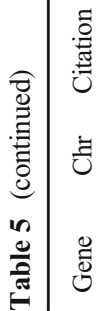


HA were heterozygous (Table 5). Therefore, this is another potentially informative SNP for hygienic behavior in honeybees.

In Drosophila, the cAMP-dependent protein kinase catalytic subunit 1 is an enzyme coded by pka-C1 gene involved in memory formation (Lee et al. 2018). This gene was not differentially expressed in our analysis as was observed in Boutin et al. (2015). Nevertheless, we identified two SNPs described in exonic region in AHB (Table 5). This could be an interesting marker since the complex hygienic behavior profile could depend on neural processes including learning of diseased brood odor cues (Goode et al. 2006).

It is important to consider that our sequenced reads from AHB were mapped against the Amel_HAv3.1 reference genome (Wallberg et al. 2019), which assembly was based at EHB. So, SNP calling analysis could reflect differences between AHB and EHB. To minimize this bias, we only considered as potentially informative SNP if it presented differences in zygosity between the two studied behavioral groups (HA and NA).

In addition to providing novel information on possible candidate genes associated with hygienic behavior in AHB, we also used our transcriptomic data to explore the presence of viruses in Brazilian AHB. Previous research demonstrated that several common honey bee viruses are frequently found in AHB in Brazil and that co-infection with multiple viruses is often found within colonies (Teixeira et al. 2008). Using our transcriptomic data, we investigated for the presence of commonly detected viruses within sequenced individual bees. Our findings revealed more than one viral sequence in some bee samples, from both the NA and HA groups (Supplementary Table 2). Two of these (DWV and BQCV) are among the most prevalent viruses in the country (Teixeira et al. 2008; Guimarães-Cestaro et al. 2020b). IAPV was also detected, corroborating a previous study finding this virus in AHB from ten apiaries located in southeastern Sao Paolo state (Teixeira et al. 2012), more than $600 \mathrm{~km}$ away, showing these viruses may be widespread in the country. Although these viruses were detected in our study, no overt symptoms were observed and all colonies appeared active and healthy upon inspection (E. Teixeira, personal observation). We also do not think there is reason to suspect that differences in virus levels between HA and NA groups biased our results, because at least one virus was detected per bee in each of the two groups (NA and HA; Supplementary Table 2). Although the presence of viral pathogens in Brazilian AHB is common, observations suggest that if colonies are properly managed and under good nutritional conditions, they can tolerate infections with no observable ill effects (Guimarães-Cestaro et al. 2020a).

Overall, this study provides a useful first step into understanding the genetic basis of hygienic behavior in AHB. We identified 49 genes with expression differences between individuals that exhibited hygienic behavior and those that did not. We called SNPs from the transcriptome data and identified relevant and potentially informative polymorphisms in genes differentially expressed in hygienic African-derived honeybees or in genes previously associated with hygienic behavior in European-derived honeybees. These markers have potential roles in hygienic behavior and represent good candidates for future breeding applications such as marker-assisted selection.

\subsection{Differential gene expression}

We assessed differential expression in bees showing hygienic activity (observed uncapping and removing sick or dead bees, HA) and nonhygienic (no signs of this behavior, NA), using high-throughput RNA sequencing. We sequenced 11 bee brain samples from individuals with HA $(n=5)$ and NA $(n=6)$. For one HA sample, the total number of reads generated was too low, and this sample was dropped from further analysis. For all other samples, we obtained $\sim 19 \mathrm{M}$ reads/ sample, with Phred scores above 30, without notable contamination by adapters. Therefore, the reads were not trimmed. The mapping statistics reported $87 \% \pm 6$ (mean $\pm \mathrm{SD}$ ) of mapped reads for NA samples and $76.5 \% \pm 12$ for HA samples (Table 2). Unmapped reads were not considered for further analysis. The A. mellifera genome version Amel_HAv3.1 reports 13,414 genes (Wallberg et al. 2019), and we found 12,376 of these to be expressed in the sequenced samples. 
We identified 49 differentially expressed genes (Fold-Change $(\mathrm{FC}) \geq 2$ and false discovery rate (FDR) $p$ value $\leq 0.05$ ) between brains of bees observed performing hygienic behavior, HA $(n=4)$, and the control group, NA ( $n=6$, Supplementary Table 3 and Fig. 1). Most were significantly upregulated $(90 \%)$ in NA samples compared with HA (Fig. 1a). Six genes had especially high magnitude differences in expression (above 40-fold over-expressed; Table 3). Two of these genes, TpnT and TpnI, code for troponin $\mathrm{T}$ and troponin I, respectively, proteins that are related to muscular contraction in insects (Herranz et al. 2005). Another gene, Melt, codes for melittin, an antimicrobial peptide with strong hemolytic activity and antimicrobial activity (Park et al. 2014). LOC 408608 codes for a disintegrin and metalloproteinase with thrombospondin 14-like motifs, and this protein has been linked previously with bee hygiene (Boutin et al. 2015).

We performed gene ontology (GO) analysis to summarize putative biological functions, molecular functions, and cellular components of the differentially expressed genes. We found functions related to defense response to bacterium and innate immune response (GO: Biological Process) enriched in the DEGs, examples being Apidaecin and Hymenoptaecin (Table 4). GO Analysis also uncovered extracellular localization and troponin complex as important cellular components, pointing to several differentially expressed peptides including two troponins, orcokinin and waprin-Phi1-like. Finally, there was also enrichment among the DEGs for molecular functions related to calcium ion binding and copper ion binding.

\subsection{Single nucleotide polymorphisms (SNPs)}

Variant detection analysis revealed 156,735 SNPs in the 10 individuals from our Africanderived honeybee transcriptome data (Supplementary Table 4). We searched for SNPs in the DEGs we identified from this study (NA vs HA contrast) and also for genes that were not differentially expressed in the current study, but cited in previous literature as associated with hygienic a

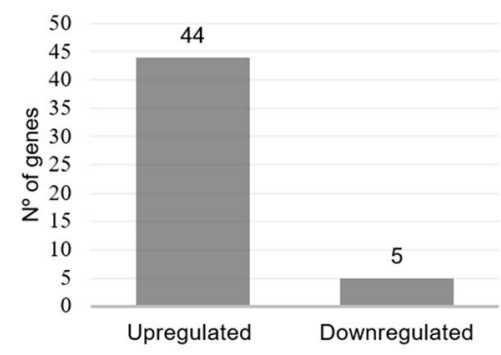

b
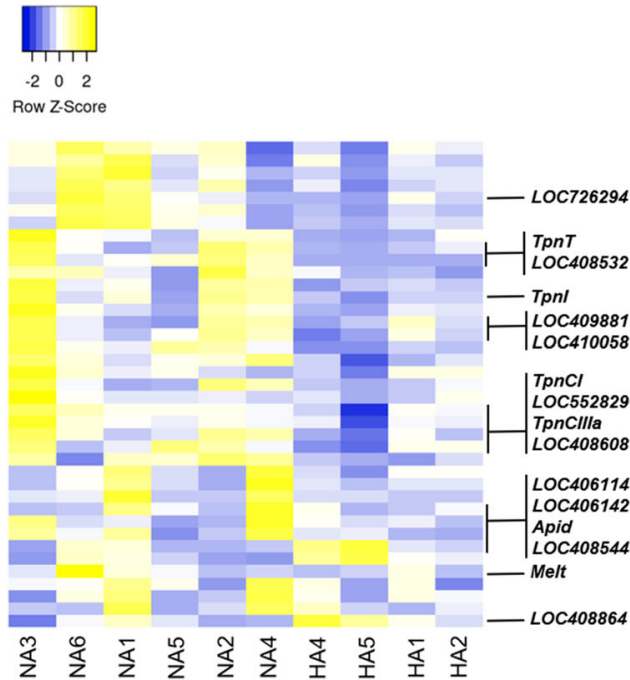

Fig. 1 Differential gene expression related with hygienic behavior in AHB. a The number of brain differentially expressed genes between individual bees showing hygienic activity (HA, $n=4)$ versus no hygienic activity (NA, $n=6$ ).s b Heatmap of RNA sequencing data characterized as row-wise Z scores in CPM. Heatmap Z-scores were calculated for each row (each gene) and each column (each sample). Heatmap displaying DEGs (FC $\geq 2$; FDR $p$ value $\leq 0.05)$ between HA $(n=4)$ versus NA $(n=6)$ related to gene ontology analysis and genes with the highest magnitude of differential expression (above 40-fold) 
behavior in honey bees (Spivak and Reuter 2001; Navajas et al. 2008; Le Conte et al. 2011; Boutin et al. 2015; Harpur et al. 2019; Conlon et al. 2019). In the group of top over-expressed (>40fold difference) DEGs between NA and HA samples, we did not find any SNPs. We did identify two relevant SNPs for the differentially expressed Apid1 gene, both $\mathrm{G} \leftrightarrow \mathrm{A}$ transitions (Table 5). These SNPs are located in the 3' untranslated region of the transcript (Table 5).

Among genes previously described as linked with hygienic behavior in European-derived subspecies of honeybees (Spivak and Reuter 2001; Navajas et al. 2008; Le Conte et al. 2011; Boutin et al. 2015; Harpur et al. 2019; Conlon et al. 2019), we found relevant SNPs in five within our African-derived honeybee dataset, Abscam, cac, Syn 1 , Pka-C1 and Obp4 . The Abscam gene showed the largest number of SNPs, with 14 (Table 5). Three SNPs (positions: 1,638,247; $1,638,290$; and $1,638,295$ ) are potentially informative in relation to hygienic behavior, as these three SNPs were all heterozygous for HA bees (1,638,247: G/A; 1,638,290 and 1,638,295: C/T) and homozygous for NA bees $(1,638,247: \mathrm{A} / \mathrm{A}$; $1,638,290$ and 1,638,295: $\mathrm{T} / \mathrm{T})$ and are located in the mRNA region of the transcript. Another two SNPs $(1,639,810$ and $1,639,819)$ were observed in all 10 samples, they are in the 3' UTR and have no apparent relationship to HA and NA phenotypes, since they were all homozygous (Table 5). The $c a c$ gene had six SNPs, all in intronic region, with one potentially informative polymorphism (position 2,521,065), which was homozygous (A/A) for the NA group and heterozygous for HA samples (T/A; Table 5).

For Syn 1, we observed three SNPs, two of them in nine samples. $\mathrm{Pka}-\mathrm{Cl}$ and $\mathrm{Obp} 4$ genes had two SNPs each (Table 5). All the markers of these genes are located in exons (Table 5).

\section{SUPPLEMENTARY INFORMATION}

The online version contains supplementary material available at https://doi.org/10.1007 /s13592-020-00834-6.

\section{ACKNOWLEDGMENTS}

This research was supported by the Brazilian research agencies São Paulo Research Foundation (FAPESP, PDE-E.W.T.) and National Council for Scientific and Technological Development (CNPq). This work was supported by the Iowa Agriculture and Home Economics Experiment Station.

\section{AUTHORS' CONTRIBUTION}

Conceptualization: EWT, AT, MVGBS.

Formal analysis: RMPD, LAGJ, EWT, MVGBS.

Project administration: EWT.

Field and observation hives experiments: EWT, MLTMFA.

Resources: JE, AT, EWT, MVGBS.

Supervision: EWT, AT.

Writing - original draft: RMPD, LAGJ, EWT, MVGBS.

Writing-review amd editing: EWT, JE, AT, MVGBS.

\section{COMPLIANCE WITH ETHICAL STANDARDS}

Conflict of interest The authors declare that they have no conflict of interest.

L'analyse transcriptomique suggère des gènes candidats pour le comportement hygiénique d'abeilles africanisées, Apis mellifera.

AHB / marqueur génétique / résistance aux maladies / sélection.

Eine Transkriptionsanalyse liefert Hinweise auf Kandidatengene für das Hygieneverhalten von Afrikanisierten Honigbienen, Apis mellifera.

AHB / genetische Marker / Krankheitsresistenz / Selektion. 


\section{REFERENCES}

Arathi, H. S., Burns, I., Spivak, M. (2000) Ethology of hygienic behaviour in the honey bee Apis mellifera L. (Hymenoptera: Apidae): behavioural repertoire of hygienic bees. Ethology, https://doi.org/10.1046 /j.1439-0310.2000.00556.x

Boutin, S., Alburaki, M., Mercier, P. L., Giovenazzo, P., Derome, N. (2015) Differential gene expression between hygienic and non-hygienic honeybee (Apis mellifera L.) hives. BMC Genomics, https://doi. org/10.1186/s12864-015-1714-y

Brosi, B.J., Delaplane, K.S., Boots, M., Roode, J.C. (2017) Ecological and evolutionary approaches to managing honeybee disease. Nat Ecol Evol, https://doi. org/10.1038/s41559-017-0246-Z

Büchler, R., Andonov, S., Bienefeld, K., Costa, C., Hatjina, F., et al (2013) Standard methods for rearing and selection of Apis mellifera queens. J. Apic. Res., https://doi.org/10.3896/IBRA.1.52.1.07

Camazine, S. (1986) Differential reproduction of the mite Varroa jacobsoni, on africanized and european honeybees. Ann. Entomol. Soc. Am. 79, 801-803.

Carneiro, F. E., Torres, R. R., Strapazzon, R., Ramírez, S. S., Guerra, J. C. V. Jr, et al (2007) Changes in the reproductive ability of the mite Varroa destructor (Anderson e Trueman) in africanized honey bees (Apis mellifera L.) (Hymenoptera: Apidae) colonies in southern Brazil. Neotrop. Entomol., https://doi. org/10.1590/s1519-566x2007000600018

Conlon, B. H., Aurori, A., Giurgiu, A., Kefuss, J., Dezmirean, D. S., et al (2019) A gene for resistance to the Varroa mite (Acari) in honey bee (Apis mellifera ) pupae. Mol. Ecol., https://doi.org/10.1111 /mec. 15080

Cremer, S., Armitage, S. A. O., Schmid-Hempel, P. (2007) Social Immunity. Curr. Biol., https://doi.org/10.1016/j. cub.2007.06.008

Danka, R. G., Harris, J. W., Villa, J. D. (2011) Expression of Varroa sensitive hygiene (VSH) in commercial VSH honey bees (Hymenoptera: Apidae). J. Econ. Entomol., https://doi.org/10.1603/ec10401

Evans, J. D., Aronstein, K., Chen, Y. P., Hetru, C., Imler, J. L., et al (2006) Immune pathways and defence mechanisms in honey bees Apis mellifera. Insect. Mol. Biol., https://doi.org/10.1111/j.13652583.2006.00682.x

Evans, J. D., Spivak, M. (2010) Socialized medicine: Individual and communal disease barriers in honey bees. Pathol., https://doi.org/10.1016/j.jip.2009.06.019

Funada, M., Hara, H., Sasagawa, H., Kitagawa, Y., Kadowaki, T. (2007) A honey bee Dscam family member, AbsCAM, is a brain-specific cell adhesion molecule with the neurite outgrowth activity which influences neuronal wiring during development. Eur. J. Neurosci., https://doi.org/10.1111/j.14609568.2006.05270.x
Gaidatzis, D., Burger, L., Florescu, M., Stadler, M. B. (2015) Analysis of intronic and exonic reads in RNA-seq data characterizes transcriptional and posttranscriptional regulation. Nat Biotechnol, https://doi. org/10.1038/nbt.3269

Gempe, T., Stach, S., Bienefeld, K., Beye, M. (2012) Mixing of honeybees with different genotypes affects individual worker behavior and transcription of genes in the neuronal substrate. PLoS One, https://doi. org/10.1371/journal.pone.0031653

Gempe, T., Stach, S., Bienefeld, K., Otte, M., Beye, M. (2016) Behavioral and molecular studies of quantitative differences in hygienic behavior in honeybees. BMC Res. Notes, https://doi.org/10.1186/s13104016-2269-y

Gerdts, J., Laurie, Dewar R., Finstrom, M. S., Edwards, T., Angove, M. (2018) Hygienic behaviour selection via freeze-killed honey bee brood not associated with chalkbrood resistance in eastern Australia. PLoS One, https://doi.org/10.1371/journal.pone.0203969

Gilliam, M., Taber III, S., Richardson, G. V. (1983) Hygienic behavior of honey bees in relation to chalkbrood disease. Apidologie, https://doi.org/10.1051 /apido: 19830103

Goode, K., Huber, Z., Mesce, K. A., Spivak, M. (2006) Hygienic behavior of the honey bee (Apis mellifera) is independent of sucrose responsiveness and foraging ontogeny. Horm. Behav., https://doi.org/10.1016/j. yhbeh.2005.08.007

Gramacho, K. P., Gonçalves, L.S., Rosenkranz, P., De Jong, D. (1999) Influence of body fluid from pinkilled honey bee pupae on hygienic behavior. Apidologie, https://doi.org/10.1051/apido:19990502

Guarna, M. M., Hoover, S. E., Huxter, E., Higo, H., Moon, K. M., et al (2017) Peptide biomarkers used for the selective breeding of a complex polygenic trait in honey bees. Sci. Rep., https://doi.org/10.1038 /s41598-017-08464-2

Guimarães-Cestaro, L., Maia, T. S., Martins, R., Alves, M. L. T. M. F., Otsuk, I. P., Message, D., Teixeira, E. W. (2020a) Nosema ceranae (Microsporidia: Nosematidae) does not cause collapse of colonies of Africanized Apis mellifera (Hymenoptera: Apidae) in tropical climate. Sociobiology., https://doi. org/10.13102/sociobiology.v67i3.4950

Guimarães-Cestaro, L., Martins, M. F., Martínez, L. C., Alves, M. L. T. M. F., Guidugli-Lazzarini, K. R., Nocelli, R. C. F., Malaspina, O., Serrão, J. E., Teixeira, E. W. (2020b) Occurrence of virus, microsporidia, and pesticide residues in three species of stingless bees (Apidae: Meliponini) in the field. Sci. Nat., https://doi.org/10.1007/s00114-020-1670-5

Hamiduzzaman, M. M., Guzman-Novoa, E., Goodwin, P. H., Reyes-Quintana, M., Koleoglu, G., et al (2015) Differential responses of africanized and european honey bees (Apis mellifera) to viral replication following mechanical transmission or Varroa destructor parasitism. J Invertebr. Pathol., https://doi.org/10.1016/j. jip.2014.12.004 
Harbo, J. R., Harris, J. W. (2009) Responses to Varroa by honey bees with different levels of Varroa Sensitive Hygiene. J. Apic. Res. Bee World, https://doi. org/10.3896/IBRA.1.48.3.02

Harpur, B. A., Guarna, M. M., Huxter, E., Higo, H., Moon, K. M., et al (2019) Integrative genomics reveals the genetics and evolution of the honey bee's social immune system. Genome Biol. Evol., https://doi. org/10.1093/gbe/evz018

Harrison, J. F., Fewell, J. H., Anderson, K. E., Loper, G. M. (2006) Environmental physiology of the invasion of the Americas by africanized honeybees. Integr. Comp. Biol., https://doi.org/10.1093/icb/ic1046

Herranz, R., Mateos, J., Mas, J. A., García-Zaragoza, E., Cervera, M., et al (2005) The coevolution of insect muscle TpnT and TpnI gene isoforms. Mol. Biol. Evol., https://doi.org/10.1093/molbev/msi223

Huang, D. W., Sherman, B. T., Lempicki, R. A. (2009a) Systematic and integrative analysis of large gene lists using DAVID bioinformatics resources. Nat. Protoc., https://doi.org/10.1038/nprot.2008.211

Huang, D. W., Sherman, B. T., Lempicki, R. A. (2009b) Bioinformatics enrichment tools: Paths toward the comprehensive functional analysis of large gene lists. Nucleic Acids Res., https://doi.org/10.1093 /nar/gkn923

Ji, T., Yin, L., Liu, Z., Liang, Q., Luo, Y., et al (2014b) Transcriptional responses in eastern honeybees (Apis cerana ) infected with mites, Varroa destructor Genet. Mol. Res., https://doi.org/10.4238/2014.October.31.4

Ji, T., Yin, L., Liu, Z., Shen, F., Shen, J. (2014a) Highthroughput sequencing identification of genes involved with Varroa destructor resistance in the eastern honeybee, Apis cerana. Genet. Mol. Res., https://doi. org/10.4238/2014.October.31.24

Jiang, S., Robertson, T., Mostajeran, M., Robertson, A. J., Qiu, X. (2016) Differential gene expression of two extreme honey bee (Apis mellifera) colonies showing Varroa tolerance and susceptibility. Insect. Mol. Biol., https://doi.org/10.1111/imb.12217

Kuromi, H., Honda, A., Kidokoro, Y. (2004) Ca2+ influx through distinct routes controls exocytosis and endocytosis at drosophila presynaptic terminals. Neuron., https://doi.org/10.1016/S0896-6273(03)00815-8

Le Conte, Y., Alaux, C., Martin, J. F., Harbo, J. R., Harris, J. W., et al (2011) Social immunity in honeybees (Apis mellifera ): Transcriptome analysis of Varroa-hygienic behaviour. Insect. Mol. Biol., https://doi. org/10.1111/j.1365-2583.2011.01074.x

Lee, P. T., Lin, G., Lin, W. W., Diao, F., White, B. H., et al (2018) A kinase-dependent feedforward loop affects CREBB stability and long term memory formation. Elife, https://doi.org/10.7554/eLife.33007

Li, W. F., Ma, G. X., Zhou, X. X. (2006) Apidaecin-type peptides: Biodiversity, structure-function relationships and mode of action. Peptides, https://doi.org/10.1016/j. peptides.2006.03.016

Masterman, R., Ross, R., Mesce, K., Spivak, M. (2001) Olfactory and behavioral response thresholds to odors of diseased brood differ between hygienic and nonhygienic honey bees (Apis mellifera L.). J. Comp. Physiol. A., https://doi.org/10.1007/s003590100216

Michelette, E. R. F., Soares, A. E. E. (1993) Characterization of preimaginal developmental stages in Africanized honey bee workers (Apis mellifera L). Apidologie, https://doi.org/10.1051/apido:19930410

Mondet, F., Alaux, C., Severac, D., Rohmer, M., Mercer, A. R., et al (2015) Antennae hold a key to Varroasensitive hygiene behaviour in honey bees. Sci. Rep., https://doi.org/10.1038/srep10454

Moretto, G., Gonçalves, L.S., De Jong, D. (1993) Heritability of africanized and european honey bee defensive behaviour against the mite Varroa jacobsoni. Rev. Bras. Genet. 16, 71-77.

Moretto, G., Mello-Jr, L. J. (1988) Varroa jacobsoni infestation of adult africanized and italian honey bees (Apis mellifera) in mixed colonies in Brazil. Genet. Mol. Biol. 22, 321-323.

Moritz, R. F. A. (1988) A reevaluation of the two-locus model for hygienic behavior in Honeybees (Apis mellifera L.). J. Hered., https://doi.org/10.1093 /oxfordjournals.jhered.a110506

Navajas, M., Migeon, A., Alaux, C., Martin-Magniette, M. L., Robinson, G. E., et al (2008) Differential gene expression of the honey bee Apis mellifera associated with Varroa destructor infection. BMC Genomics, https://doi.org/10.1186/1471-2164-9-301

Nicodemo, D., De Jong, D., Couto, R. H. N., Malheiros, E. B. (2013) Honey bee lines selected for high propolis production also have superior hygienic behavior and increased honey and pollen stores. Genet. Mol. Res., https://doi.org/10.4238/2013.December.19.12

Oxley, P. R., Spivak, M., Oldroyd, B. P. (2010) Six quantitative trait loci influence task thresholds for hygienic behaviour in honeybees (Apis mellifera). Mol. Ecol., https://doi.org/10.1111/j.1365-294X.2010.04569.x

Park, D., Jung, J. W., Lee, M. O., Lee, S. Y., Kim, B., et al (2014) Functional characterization of naturally occurring melittin peptide isoforms in two honey bee species, Apis mellifera and Apis cerana. Peptides, https://doi.org/10.1016/j.peptides.2014.01.026

Parker, R., Guarna, M. M., Melathopoulos, A. P., Moon, K., White, R., et al (2012) Correlation of proteomewide changes with social immunity behaviors provides insight into resistance to the parasitic mite, Varroa destructor, in the honey bee (Apis mellifera). Genome Biol., https://doi.org/10.1186/gb-2012-13-9-r81

Peng, Y. S., Marston, J. M. (2008) Filtering mechanism of the honey bee proventriculus. Physiol. Ent., https://doi. org/10.1111/j.1365-3032.1986.tb00434.x

Piccirillo, G. A., De Jong, D. (2003) The influence of brood comb cell size on the reproductive behavior of the ectoparasitic mite Varroa destructor in africanized honey bee colonies. Genet. Mol. Res. 2, 36-42

Rauch, S., Ashiralieva, A., Hedtke, K., Genersch, E. (2009) Negative correlation between individual-insect-level virulence and colony-level virulence of Paenibacillus larvae, the etiological agent of american foulbrood of 
honeybees. Appl. Environ. Microbiol., https://doi. org/10.1128/AEM.02839-08

Ray, A. M., Lopez, D. L., Martinez, F. I., Galbraith, D. A., Rose, R., Van Engelsdorp, D., Rosa, C., Evans, J. D., Grozinger, C. M. (2020) Distribution of recently identified bee-infecting viruses in managed honey bee (Apis mellifera) populations in the USA. Apidologie, https://doi.org/10.1007/s13592-020-00757-2

Rosenkranz, P., Aumeier, P., Ziegelmann, B. (2010) Biology and control of Varroa destructor. J. Invertebr. Pathol., https://doi.org/10.1016/j.jip.2009.07.016

Rothenbuhler, W. C. (1964) Behavior genetics of nest cleaning in honey bees. IV . Responses of F1 and backcross generations to disease-killed brood. Am. Zool., https://doi.org/10.1093/icb/4.2.111

Schneider, S. S., DeGrandi-Hoffman, G., Smith, D. R. (2004) The african honey bee: Factors contributing to a successful biological invasion. Annu. Rev. Entomol., h t t p s ://doi.org/10.1146/annurev. ento.49.061802.123359

Simone-Finstrom, M. D., Spivak, M. (2012) Increased resin collection after parasite challenge: A case of self-medication in honey bees? Plos One, https://doi. org/10.1371/journal.pone.0034601

Spivak, M., Downey, D. L. (1998) Field assays for hygienic behavior in honey bees (Hymenoptera: Apidae). J. Econ. Entomol. 91 (1), 64-70.

Spivak, M., Masterman, R., Ross, R., Mesce, K. A. (2003) Hygienic behavior in the honey bee (Apis mellifera $\mathrm{L}$.) and the modulatory role of octopamine. J. Neurobiol., https://doi.org/10.1002/neu.10219

Spivak, M., Reuter, G. S. (1998) Performance of hygienic honey bee colonies in a commercial apiary. Apidologie, https://doi.org/10.1051/apido:19980308

Spivak, M., Reuter, G. S. (2001) Varroa destructor infestation in untreated honey bee (Hymenoptera: Apidae) colonies selected for hygienic behavior. J. Econ. Entomol., https://doi.org/10.1603/0022-049394.2.326

Spötter, A., Gupta, P., Nürnberg, G., Reinsch, N., Bienefeld, K. (2012) Development of a 44K SNP assay focussing on the analysis of a Varroa-specific defence behaviour in honey bees (Apis mellifera carnica). Mol. Ecol. Resour., https://doi.org/10.1111/j.17550998.2011.03106.x
Sultan, M., Schulz, M. H., Richard, H., Magen, A., Klingenhoff, A., et al. (2008) A global view of gene activity and alternative splicing by deep sequencing of the human transcriptome. Science 321, 956-960

Teixeira, E. W., Chen, Y., Message, D., Boncristiani, H. F., Pettis, J., Evans, J. D. (2012) Israeli acute paralysis virus in Africanized honey bees in southeastern Brazilian Apiaries. J. Apic. Res., https://doi.org/10.3896 /IBRA.1.51.3.11

Teixeira, E. W., Chen, Y., Message, D., Pettis, J., Evans, J. D. (2008) Virus infections in Brazilian honey bees. Journal of Invertebrate Pathology 99, 117-119.

Tsuruda, J. M., Harris, J. W., Bourgeois, L., Danka, R. G., Hunt, G. J. (2012) High-resolution linkage analyses to identify genes that influence Varroa sensitive hygiene behavior in honey bees. PLoS One, https://doi. org/10.1371/journal.pone.0048276

Wagoner, K. M., Spivak, M., Rueppell, O. (2018) Brood affects hygienic behavior in the honey bee (Hymenoptera: Apidae). J. Econ. Entomol., https://doi. org/10.1093/jee/toy 266

Wallberg, A., Bunikis, I., Pettersson, O. V., Mosbech, M. B., Childers, A. K., Evans, J. D., Mikheyev, A. S., Robertson, H. M., Robinson, G. E., Webster, M. T. (2019) A hybrid de novo genome assembly of the honeybee, Apis mellifera, with chromosome-length scaffolds. BMC genomics, https://doi.org/10.1186 /s12864-019-5642-0

Wilson-Rich, N., Spivak, M., Fefferman, N. H., Starks, P. T. (2009) Genetic, individual, and group facilitation of disease resistance in insect societies. Annu. Rev. Entomol., https://doi.org/10.1146/annurev. ento.53.103106.093301

Wu, Q., Patočka, J., Kuča, K. (2018) Insect antimicrobial peptides, a mini review. Toxins (Basel), https://doi. org/10.3390/toxins10110461

Xu, P., Shi, M., Chen, X. (2009) Antimicrobial Peptide Evolution in the Asiatic Honey Bee Apis cerana. PLoS ONE, https://doi.org/10.1371/journal.pone.0004239

Publisher's note Springer Nature remains neutral with regard to jurisdictional claims in published maps and institutional affiliations. 